\title{
Study on the process of Carbon Nanotubes modified
} Urea-Formaldehyde Resin Adhesive Shaobo ZHANG $^{1, a}$, Yu WANG ${ }^{1, b}$ and Jintian HUANG ${ }^{1, c^{*}}$

${ }^{1}$ college of material science and art design, Inner Mongolia agricultural university, Hohhot 010018 , Inner Mongolia, China

a 879585820@qq.com, b499436197@qq.com, cjintian_h@163.com

* Jintian HUANG

Keywords: Urea-formaldehyde, Carbon Nanotubes, Optimal solution

Abstract. Using mechanical blending of carbon nanotubes (CNTs) composite urea-formaldehyde (UF) resin adhesives. The ultrasonic time, the amount of CNTs, ultrasonic power orthogonal experi ment was carried out. It is concluded that the important order of effect factors on free formaldehyde emission to UF resin adhesives: the amount of carbon nanotubes, ultrasonic time, ultrasonic frequen cy; The important order of effect factors on the shear strength of UF resin adhesives is ultrasonic po wer, the amount of CNTs, ultrasonic time; Preparation of composite CNTs/UF resin adhesives the o ptimal solution is: ultrasonic time of $30 \mathrm{~min}$, ultrasonic power of $600 \mathrm{~W}$, the amount of CNTs of 0.3 g.

\section{Introduction}

In 1991, the Japanese scientists (Iijima) ${ }^{[1]}$ for the first time discovered carbon nanotubes(CNTs). The chemical structure and atomic structure of CNTs are very simple, but there are very abundant physical and chemical properties. 1-2nm diameter of CNTs, young's modulus can reach $1 \mathrm{TPa}^{[2]}$, with diamond almost equal; The tensile strength of up to $150 \mathrm{MPa}^{[3]}$; The elongation of the CNTs can reach $20 \%$, with good toughness; The strength of the CNTs is approximately 100 times of steel, and the density is only $1 / 6$ of the steel. If CNTs were modified the other engineering materials, the new material strength, abrasion resistance and fatigue resistance performance has greatly increase ${ }^{[4]}$.

Urea-formaldehyde (UF) resin adhesives have many advantages, such as technological process is simple and low cost, so man-made board with UF is widely used, but the downside is more obvious, the agglutination intensity is weak, the free formaldehyde emission is high, in order to improve this situation, Huang ${ }^{[5]}$ etc with CNTs modified UF resin adhesives to improve the shear strength of UF resin adhesives and reduce the free formaldehyde emission. in this paper, by changing the ultrasoni $\mathrm{c}$ time, content of CNTs and ultrasonic power, studying the orthogonal experiment, it is concluded $\mathrm{t}$ he important order of effect factors on free formaldehyde emission to UF resin adhesives, the impor tant order of effect factors on the shear strength of UF resin adhesives and the optimal solution of $\mathrm{Pr}$ eparation of composite CNTs/UF resin adhesives .

\section{Experimental}

The preparation of $\mathbf{C N T s} / \mathbf{U F}$ resin adhesives. The preparation of UF resin adhesive By Huang ${ }^{[5]}$ methods. Different amount of CNTs added to UF resin adhesives, different ultrasonic time, differen $\mathrm{t}$ ultrasonic power.

Determine the free formaldehyde emission of CNTs/UF resin adhesives $5.00 \mathrm{~g}$ glue, add 30.0 $0 \mathrm{ml}$ of distilled water and $20.00 \mathrm{ml}$ anhydrous ethanol, with $10 \% \mathrm{NH} 4 \mathrm{Cl}$ solution $\mathrm{pH}=6.5$, add 10 . $00 \mathrm{ml} 10 \% \mathrm{NH} 4 \mathrm{Cl}$ solution, add $1.00 \mathrm{~mol} / 1 \mathrm{NaOH}$ solution $10.00 \mathrm{ml}$, shake in full, in $20{ }^{\circ} \mathrm{C}$ for 30 minutes. In $1.00 \mathrm{~mol} / \mathrm{L}$ hydrochloric acid standard solution modulation, until $\mathrm{pH}=6.5$. Twice the sa me test, record the data consumption of hydrochloric acid standard solution, take two test numerical average.

$$
\mathrm{F}=0.03003 \times 6 \times(\mathrm{V} 1-\mathrm{V} 2) \times \mathrm{C} / 4 \mathrm{~g} \times 100
$$


$\mathrm{F}$ : the free formaldehyde emission (\%); C: molar concentration of hydrochloric acid solution (mol/L); V1: blank consumption volume of hydrochloric acid $(\mathrm{mL})$; V2: determination of test cost of hydroc hloric acid volume $(\mathrm{mL}) ; \mathrm{C}(\mathrm{HCl})=1 \mathrm{~mol} / \mathrm{L} ; \mathrm{G}$ : sample quality $(\mathrm{g})$.

Shear strength test With reference to GJB 1709-1993 adhesive shear strength test method at lo w temperature Sheet specimen material: the plank cypress, preliminary drying, drying to the moistu re content from $5 \%$ to $8 \%$, will be tested in combination with surface planing, thickness of about 1$2 \mathrm{~mm}$. Specimen agglutination: use the beaker said take $10 \mathrm{~g}$ sample, add $1 \%$ ammonium chloride, a nd then mixing, mixing ammonium chloride fully into the adhesive. Shear strength test: use a ruler measuring on the surface of the specimen glue joint width and length (a) (b), bonding method as sho wn in figure 1 Shear strength calculation formula: $F=p /(a \times b)$

Fig. 1. Shear strength measurement

CNTs/UF resin adhesives orthogonal experiment design For ultrasonic time, the amount of C NTs and ultrasonic power three factors orthogonal design of experiment measuring shear strength a nd the quantity of free formaldehyde emission, orthogonal test are shown in table 1 (a) (b)

table 1 (a)

\begin{tabular}{llll}
\hline & A & B & C \\
Ultrasonic & Content of Ultrasonic \\
time & CNTs \\
& $(\min )$ & $(\mathrm{g})$ & $\begin{array}{c}\text { power } \\
(\mathrm{w})\end{array}$ \\
\hline 1 & 10 & 0.1 & 400 \\
2 & 20 & 0.2 & 600 \\
3 & 30 & 0.3 & 800 \\
\hline
\end{tabular}

(b)

\begin{tabular}{|c|c|c|c|c|c|}
\hline & A & B & $\mathrm{C}$ & \multirow{2}{*}{$\begin{array}{l}\text { Shear } \\
\text { strength } \\
\text { (Mpa) }\end{array}$} & \multirow{2}{*}{$\begin{array}{l}\text { Free } \\
\text { formaldehyde } \\
(\%)\end{array}$} \\
\hline & $\begin{array}{l}\text { Ultrasonic } \\
\text { time } \\
(\min )\end{array}$ & $\begin{array}{l}\text { Content } \\
\text { of CNTs } \\
(\mathrm{g})\end{array}$ & $\begin{array}{l}\text { Ultrasonic } \\
\text { power } \\
\text { (w) }\end{array}$ & & \\
\hline 1 & 10 & 0.1 & 400 & 1 & 0.67 \\
\hline 2 & 20 & 0.1 & 600 & 1.1 & 0.65 \\
\hline 3 & 30 & 0.1 & 800 & 1.05 & 0.69 \\
\hline 4 & 10 & 0.2 & 600 & 1.16 & 0.68 \\
\hline 5 & 20 & 0.2 & 800 & 1.01 & 0.63 \\
\hline 6 & 30 & 0.2 & 400 & 0.76 & 0.61 \\
\hline 7 & 10 & 0.3 & 800 & 1.37 & 0.57 \\
\hline 8 & 20 & 0.3 & 400 & 1.02 & 0.55 \\
\hline 9 & 30 & 0.3 & 600 & 1.17 & 0.52 \\
\hline
\end{tabular}

Table 2 for the ultrasonic time, the amount of CNTs, ultrasonic power of CNTs/UF resin adhesiv e composite free formaldehyde emission.

Table 3 for the ultrasonic time, the amount of CNTs, ultrasonic power of CNTs/UF resin adhesive shear strength of composite material. 
Table 2

\begin{tabular}{|c|c|c|c|c|}
\hline Variable & & $\bar{A}$ & $\bar{B}$ & $\bar{C}$ \\
\hline The free & K1 & 1.92 & 2.01 & 1.83 \\
\hline formaldehyde & $\mathrm{K} 2$ & 1.83 & 1.92 & 1.85 \\
\hline emission & K3 & 1.82 & 1.64 & 1.89 \\
\hline Range & $\mathrm{R}$ & 0.1 & 0.37 & 0.06 \\
\hline $\begin{array}{c}\text { Important } \\
\text { order }\end{array}$ & & \multicolumn{3}{|c|}{$\mathrm{BAC}$} \\
\hline $\begin{array}{l}\text { Optimal } \\
\text { solution }\end{array}$ & & \multicolumn{3}{|c|}{ B3A3 C1 } \\
\hline
\end{tabular}

Table 3

\begin{tabular}{lcccc}
\hline Variable & & $\mathrm{A}$ & $\mathrm{B}$ & $\mathrm{C}$ \\
\hline \multirow{2}{*}{ Shear } & $\mathrm{K} 1$ & 3.53 & 3.15 & 2.78 \\
strength & $\mathrm{K} 2$ & 3.13 & 2.93 & 3.43 \\
& $\mathrm{~K} 3$ & 2.98 & 3.56 & 3.43 \\
\cline { 1 - 1 } Range & $\mathrm{R}$ & 0.55 & 0.63 & 0.65 \\
$\begin{array}{c}\text { Important } \\
\text { order }\end{array}$ & \multicolumn{3}{c}{ CBA } \\
$\begin{array}{c}\text { Optimal } \\
\text { solution }\end{array}$ & \multicolumn{3}{c}{ C2B3A1 或 C3B3A1 } \\
\hline
\end{tabular}

As is seen from table 2 that the order of range is:B: $0.37>\mathrm{A}: 0.1>\mathrm{C}: 0.06$, showing that the important order of relevant factors that effect free formaldehyde emission of the $\mathrm{CNTs} / \mathrm{UF}$ resin adhesives is: the amount of CNTs $>$ ultrasonic time $>$ ultrasonic frequency.

Determine the best solutions in each group by the size of the K1, K2, K3. Choose the minimum value in the A,B,C as optimal solution of free formaldehyde emission, the results is $\mathrm{B}$ : $\mathrm{K} 3=1.64, \mathrm{~A}$ : $\mathrm{K} 3=1.82, \mathrm{C}: \mathrm{K} 1=0.83$, showing that CNTs of $0.3 \mathrm{~g}$, ultrasonic time of 30 minutes, ultrasonic frequency of $400 \mathrm{~W}$ is the optimal solution. Under the optimal solution, the free formaldehyde emission of CNTs/UF resin adhesive glue can be effectively decreased.

As is seen from table 3 that the order of range is:C:0.65 > B:> A:0.63 0.55, determined by the range order of the ultrasonic time, the amount of CNTs, and ultrasonic power, showing that the important order of relevant factors that effect the shear strength of CNTs/UF resin adhesives is: $\mathrm{C}, \mathrm{B}, \mathrm{A}$, namely: ultrasonic power, the amount of CNTs, ultrasonic time.

Determine the best solutions in each group by the size of the K1, K2, K3. Choose the maximum value of $\mathrm{K}$ in the $\mathrm{A}, \mathrm{B}, \mathrm{C}$ as optimal solution of shear strength performance, the results is $\mathrm{C}$ : $\mathrm{K} 2=3.43$, B: $\mathrm{K} 2=3.56, \mathrm{~A}: \mathrm{K} 1=3.53$ and $\mathrm{C}: \mathrm{K} 2=3.43$, $\mathrm{B}: \mathrm{K} 2=3.56, \mathrm{~A}: \mathrm{K} 1=3.53, \mathrm{~K} 2$, $\mathrm{K} 3$, in group $\mathrm{C}$ the values of $\mathrm{K} 2$ and $\mathrm{K} 3$ are same, the power of $\mathrm{K} 2$ is $600 \mathrm{~W}$, the power of $\mathrm{K} 3$ is $800 \mathrm{~W}$, based on the principle of lower consumption, we choose the power of $600 \mathrm{~W}$, just the $\mathrm{K} 2$, in other words, the optimal solution is the amount of CNTs of $0.3 \mathrm{~g}$, ultrasonic time of 30 minutes, and ultrasonic frequency of $600 \mathrm{~W}$. Under the optimal solution, the shear strength of the CNTs/UF resin adhesive of adhesion agent is effectively improved.

Through the analysis above, we obtain two groups of optimum scheme. The optimal solution of the free formaldehyde emission is: CNTs of $0.3 \mathrm{~g}$, ultrasonic time of 30 minutes, ultrasonic frequency of $400 \mathrm{~W}$. The optimal solution of shear strength is:0.3 $\mathrm{g}$ for the amount of CNTs, ultrasonic time of 30 minutes, and ultrasonic frequency of 600W.As to the two groups of optimal solution, comprehensive balance method is used in analyze.

For A: ultrasonic time. Shear strength belongs to third main factors, free formaldehyde emission belong to the secondary factors, so choose the free formaldehyde emission, A3.

For B: the amount of CNTs. The largest of shear strength and free formaldehyde emission both are B3, so choose factors of B3.

For C: ultrasonic power. The effects of ultrasonic power on free formaldehyde emission is third, the difference value is small, but for bonding strength, it is the primary factor, so $\mathrm{C} 2$ is selected.

Based on the analysis above,C2B3A3 is choosed as the. The optimal solution of the preparation of CNTs/UF resin glue adhesion agent is: ultrasonic time of 30 minutes, ultrasonic power of $600 \mathrm{~W}$, the amount of CNTs of $0.3 \mathrm{~g}$.

\section{Conclusions}

In this study, CNTs was used to modified UF resin adhesives, realized the preparation of the CNTs/ UF resin glue adhesion agent, range is used to determine the important order of effect factors on fre 
e formaldehyde emission to UF resin adhesives: the amount of carbon nanotubes, ultrasonic time, ul trasonic frequency; The important order of effect factors on the shear strength of UF resin adhesives is ultrasonic power, the amount of CNTs, ultrasonic time. Through value analysis of $\mathrm{K}$ in the ortho gonal experiment, and comprehensive balance method to get the optimal solution is: ultrasonic time of 30 minutes, ultrasonic power of $600 \mathrm{~W}$, the amount of CNTs of $0.3 \mathrm{~g}$.

\section{Acknowledgements}

This work was supported by Research Fund for the Doctoral Program of Higher Education of China under grant no. 20131515110013, the Inner Mongolia Autonomous Region applied technology research and development funds plan (20130317) and science research innovation projects of the Inner Mongolia Autonomous Region for graduate under grant no.B20141012902Z.

\section{References}

[1] Li jima S. [J]. Nature, 1991, 354: 56-58.

[2] Salvetat J P, Andrew G, et al. [J]. Phys Rev Lett, 1999, Vol. 82 (5): 944-947.

[3] Bower C, Rosen. [J]. Appl Phy Lett, 1999, Vol. 74: 3317-3319.

[4] Wei-guo Jiang, Shoutao Wei, et al. [J]. Chemical New Materials, 2007, 35 (7) :7-8. (In Chinese)

[5] JinTian Huang, KunLing Tie and YanFei Pan. [J]. Asian Journal of Chemistry, Vol. 25, No. 14 (2013), 7997-8000. 